\title{
A simulation-based Data Envelopment Analysis (DEA) model to evaluate wind plants locations
}

\author{
Hossein Sameia $^{\mathrm{a}^{*}}$ and Meysam Arvan ${ }^{\mathrm{b}}$
}

${ }^{a}$ Department of Mechanical and Industrial Engineering, Islamic Azad University, Qazvin branch, Iran

${ }^{b}$ Institute of Transport and Logistics Studies, The University of Sydney Business School, Sydney, NSW 2000, Australia

\begin{tabular}{l}
\hline C H R O N I C L E \\
\hline Article history: \\
Received July 10, 2014 \\
Accepted December 31, 2014 \\
Available online \\
January 32015 \\
\hline Keywords: \\
Wind Plants \\
Clean Energies \\
Turbine Power Distribution \\
Function \\
Simulation \\
Data Envelopment Analysis \\
(DEA) \\
Simulation-Based DEA
\end{tabular}

\section{Introduction}

Wind energy, the world's fastest growing energy source is a free, clean, renewable, never-ending energy source that is totally accommodated with the environment. The uneven heating of the atmosphere by the sun, the irregularities of the earth's surface, and the rotation of the earth cause winds (http://windeis.anl.gov). Wind is available in large quantities and does not make pollution. The point that mostly makes this source of energy important is that no matter how much it is used today; there will still be the same supply in the future. Considering these facts, utilizing this kind of energy is rapidly increasing in the world. Despite all the benefits of wind power, there are some challenges related to it. The major challenge to use wind as a source of energy is that it is intermittent and does not always blow when electricity is needed. Besides, not all kind of winds can be harnessed to meet the timing of

* Corresponding author. Tel: +98 (21) 88460871

E-mail address: h.sameie1988@gmail.com (H. Sameie)

(C) 2015 Growing Science Ltd. All rights reserved. doi: $10.5267 /$ j.ds1.2015.1.001

\begin{abstract}
As the world is getting overpopulated and over polluted the human being is seeking to utilize clean energy sources that is accessible everywhere on the planet earth. This source of energy cannot be stored for later use; therefore, environmental circumstances and geographical location of wind plants are crucial matters. This study proposes a model to decide on the the geographical position of the nominated location such as wind speed; altitude; mean temperature; and humidity; a simulation method is applied on the problem. Other factors such as the time that a plant is out of service and demand fluctuations also have been considered in the simulation phase. Moreover, a probability distribution function is calculated for the turbine nominated locations for wind farm. The proposed model takes into account several important elements of the problems. Elements such as land cost; average power received from the wind blowing; demand point population etc. are considered at the same time to select the optimum location of wind plants. Finally, the model is applied on a real case in order to demonstrate its reliability and applicability.
\end{abstract}

(C) 2015 Growing Science Ltd. All rights reserved. 
electricity demands. Moreover, wind energy cannot be stored. However, electricity generated by wind can be stored, if batteries are used. Additionally, efficient wind sites are often located in locations that are far from areas that electric power is in demand (such as factories and cities). Having all these deficiencies in the mind, locating the wind power facilities comes to immense importance. An ideal locating of the wind plants can cope with most of these deficiencies. For instance, if a set of wind plants be located in different locations with different wind characteristics and demand fluctuation in a way that they cover their out of service time, low blowing time and so on; it would diminish the effect of wind intermittency. In Addition, an appropriate locating can help to find less costly land and more usable places. Nevertheless, recently there are wind plants placed in offshore, however it is not always reachable and feasible to build a wind plant in water.

Location decisions are used in any field of facility establishment. The term "location" refers to the modeling, formulation, and solving of a class of problems that can best be described as setting facilities in some given space. There are four components that characterize location problems (Bhatnagar \& Sohal, 2005):

1) Customers, who are presumed to be already located at points or on routes,

2) Facilities that will be located,

3) A space in which customers and facilities are located, and

4) A metric that indicates distances or times between customers and facilities

Applications of location problems vary from gas stations and fast food outlets to landfills and power plants. In a basic perspective, the facility location problem consists of a set of potential facility sites ' $L$ ' where a facility can be opened or not, and a set of demand points ' $D$ ' that must be serviced. The goal is to pick a subset of facilities ' $F$ ' to be open, to minimize the sum of distances from each demand point to its nearest facility, plus the sum of opening costs of the facilities. In recent years, an increasing tendency has been shown to work on the location optimization in the field of new and clean energies (Aytun Ozturk \& Norman, 2004; Azadeh et al., 2008; Bowling et al., 2011; Rentizelas et al., 2009). This study contributes to the literature by proposing a model that performs to find the most appropriate location for establishing a wind farm. The model is a combination of discrete event simulation (DES) method and data envelopment analysis (DEA). The simulation phase calculates some factors that directly influence the efficiency of the location that a plant should be built in. This study proposes a probability density distribution function for the power produced by a wind turbine that helps the simulation phase to be more precise. Measures such as altitude, annual mean temperature, and humidity that affect the probability distribution are considered in the paper. The results of the simulation phase are input to the DEA phase that combines the simulation results with the other factors that are deterministic. Factors such as cost of land; proximity to demand points; weather situation and so on that are discussed in detail in the section five; are directly considered in the DEA model. Finally, DEA ranks all nominated locations. Overview of the research is shown in Fig. 1.

The rest of the paper is organized as follows: First, an overview of the literature of the subject is presented in section 2. Then the method of the paper is discussed in two parts in section 3. The first part of the method section deals with DEA and the second part contribute to discrete event simulation. The third section presents the model. A numerical example has been presented in the fourth section. Finally, the conclusion of the paper is discussed in section five. 


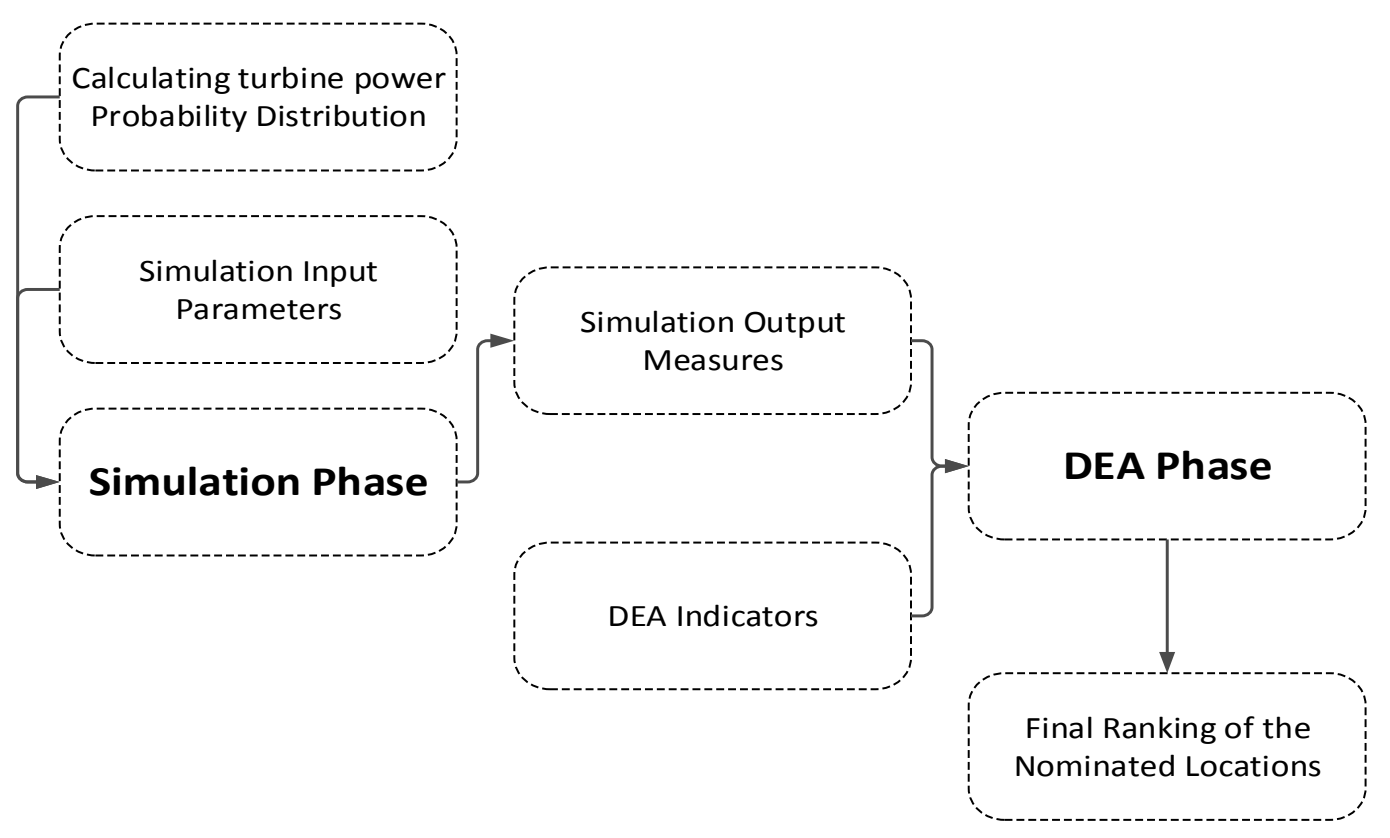

Fig. 1. Overview of the research

\section{Literature Review}

In this section, we review some of important studies that are related to this study. First, the body of literature that is related to the studies that include facility location problem using simulation or DEA is overviewed. Then a review of studies that have utilized the combination of aforementioned methods is presented. Certainly, the most related study to this work is done by Azadeh et al. (2011). They proposed an integrated hierarchical data envelopment analysis to optimize the location of wind plants. Moreover, they used two multivariable methods namely Principal Component Analysis (PCA) and Numerical Taxonomy (NT) to validate the results of the DEA model. They also introduced several indicators that are suitable for assessing a candidate wind plant's location. The indicators they presented were population and human labor; distance of power distribution networks; land cost; the average wind blow; the intensity of natural disasters occurrence; quantity of proper geological areas and quantity of proper topographical areas. In another work, Azadeh et al. (2008) presented a model for deciding on location of solar plants. They utilized an integrated hierarchical approach by DEA, PCA, and NT. They used PCA and NT to validate the results of the DEA. Klimberg and Ratick (2008) developed location modeling formulations to find optimal and efficient facility location/allocation patterns. They utilized data envelopment analysis efficiency measures to execute the model. Their model simultaneously considered the interaction of spatial efficiency of different location patterns using least cost objective and the facility efficiencies at those sites by DEA. Evaluating performance and efficiency of 22 seaports in East Africa and the Middle East was done by Al-Eraqi et al. (2007). They used DEA to perform their model. Mitropoulos et al. (2012) suggested a methodology to consider health service provider efficiencies based on multiple measures. They took advantage of DEA and Integer Programming (IP) location allocation models to do so. Guo (2009) proposed a model to evaluate the efficiencies of objects with fuzzy input and output data. He utilized fuzzy DEA for solving the problem. The primary factors that he used in the paper's case study were rent of establishment; traffic amount; level of security; consumer consumption level and competition level.

Andor and Hesse (2011) used a Monte Carlo experimentation to analyze the optimal approach for determining individual efficiency scores. They also compared the two most popular estimation 
methods, DEA and Stochastic Frontier Analysis (SFA). McMullen and Frazier (1999) tested several heuristics to select the best assembly line balancing strategy by using data envelopment analysis. They obtained several output performance measures from the simulation.

These measures were used as outputs for DEA. In a recent study, to select a site for wind farms, Chatterjee and Bose (2013) proposeed a COPRAS (COmplex PRoportional ASsessment) based multicriteria decision-making (MCDM) methodology under fuzzy environment with the help of multiple decision makers. Their study's purpose was to focus the applicability of COPRAS-F as a strategic decision making tools to handle the group decision-making problems.

Despite the researches which have taken nonparametric and probabilistic methods into account, numerous researches have applied mathematical modeling methods in order to address location problem (Arvan et al., 2014; Gendron et al., 2013; Gollowitzer \& Ljubić, 2011; Marín, 2011).

\section{Method}

\subsection{Data envelopment analysis}

DEA is a linear programming based method. First, the idea of DEA initiated by Farrell (1957) but later it developed by Charnes, Cooper, and Rhodes (1978). DEA method has been increasingly used since the pioneering work of Charnes et al. (1978) in different fields to evaluate efficiency of a set of homogenous DMUs. DEA commonly applies in different fields such as electrical industries; hospitals; university departments; refineries; location problems and manufacturing enterprises etc. in order to measure the efficiency. DEA is a nonparametric method so it can be used for determining the quantity of inefficiency in each input relative to each output. In this section, a brief review of the salient features of DEA is done. For more investigation the reader is referred to Abdollahi et al. (2014), Andersen and Petersen (1993), Charnes (1994) and Ganley and Cubbin (1992).

Generally, there are two basic models for DEA: Constant Returns-to-Scale (CRS) or CCR model and Variable Returns-to-Scale (VRS) or BCC model. Both models could be either input-orientated or output-orientated. In input oriented, the outputs are assumed constant and accordingly DEA method defines the frontier by looking for the maximum possible proportional reduction in the input usage. In output-oriented, input levels are fixed and DEA method seeks to maximize the proportional increase in output value. The efficiency score when there are multiple inputs and outputs is defined as (Talluri, 2000):

$$
E=\frac{\text { Weighted Sum of Outputs }}{\text { Weighted Sum of Inputs }}
$$

Let $\left(X_{1}, X_{2}, \ldots, X_{m}\right)$ be the input values, $\left(V_{1}, V_{2}, \ldots, V_{m}\right)$ weights assigned to them, $\left(Y_{1}, Y_{2}, \ldots, Y_{s}\right)$ be the output values and $\left(U_{1}, U_{2}, \ldots, U_{s}\right)$ weights assigned to outputs with n decision-making units, models are as follows (Cooper et al., 2011):

A basic input oriented CCR model:

$$
\begin{aligned}
& \max Z=\sum_{R=1}^{S} u_{r} y_{r 0} \\
& \text { subject to } \\
& \sum_{i=1}^{m} v_{i} x_{i 0}=1 \\
& \sum_{r=1}^{S} u_{r} y_{r j}-\sum_{i=1}^{m} x_{i j} v_{i} \leq 0 \\
& u_{r}, y_{r j} \geq 0
\end{aligned}
$$




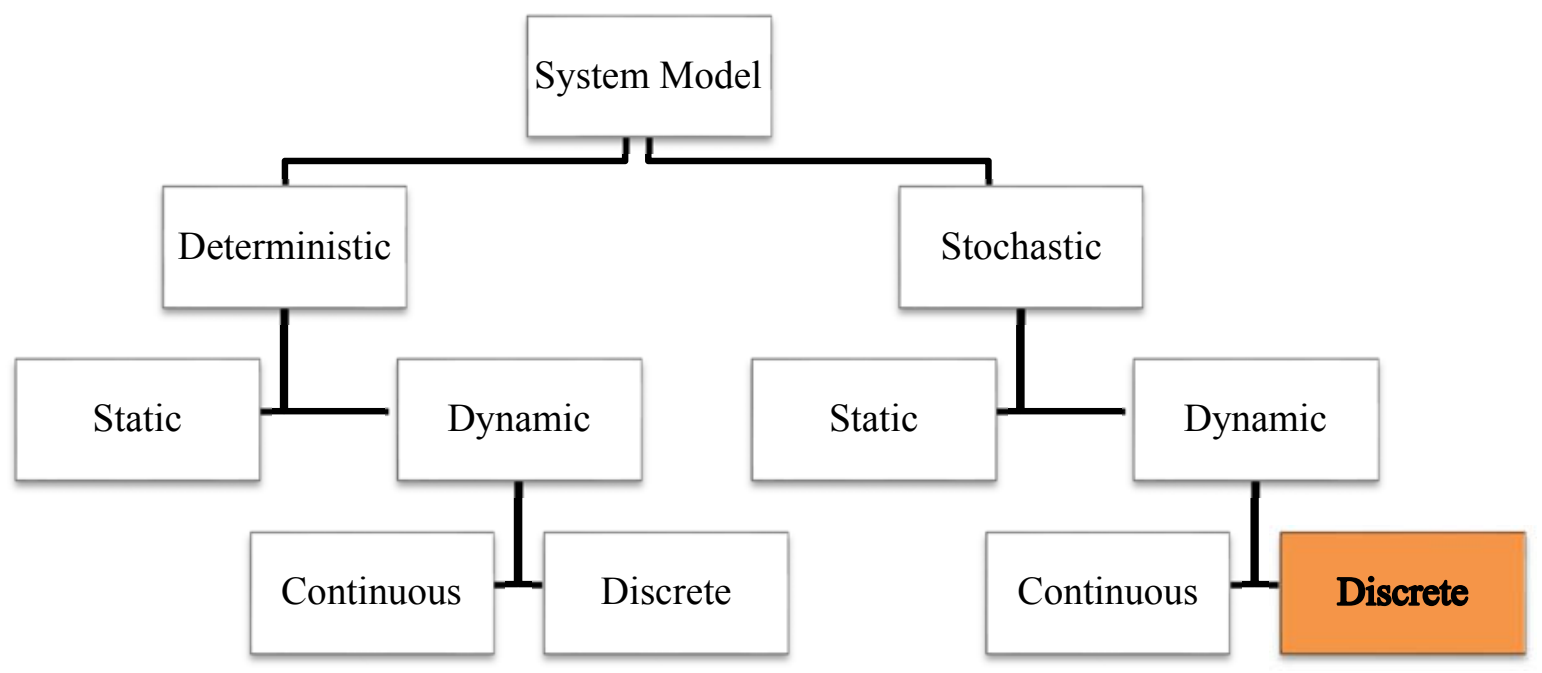

Fig. 2. The position of discrete event simulation in system structure

A basic input oriented BCC model:

$$
\begin{aligned}
& \min \mathrm{Z}=\sum_{i \in m} v_{i} x_{i 0} \\
& \text { subject to } \\
& \sum_{r \in s} u_{r} y_{r 0}=1 \\
& \sum_{r \in s} u_{r} y_{r j}-\sum_{i \in m} v_{i} x_{i j} \leq 0 \\
& u_{r}, v_{i} \geq 0
\end{aligned}
$$

A basic input oriented BCC model:

$$
\begin{aligned}
& \max \mathrm{Z}=\sum_{r \in s} u_{r} y_{r 0}+w \\
& \sum_{i \in m} v_{r} x_{i 0}=1 \\
& \sum_{r \in S} u_{r} y_{r j}-\sum_{i \in m} v_{i} x_{i j}+w \leq 0
\end{aligned}
$$

$u_{r}, v_{i} \geq 0$

The main difference between $\mathrm{CCR}$ and $\mathrm{BCC}$ models is existence of $\mathrm{W}$ in $\mathrm{BCC}$ model that defines return to scale measure (Cooper, 2011).

\subsection{Discrete Event Simulation:}

Simulation allows one to specify a system accurately by using the logically complex, and often nonalgebraic, variables and constraints. Complex and stochastic systems can therefore be modeled through simulation (Abdollahi, Arvan, Omidvar, \& Ameri, 2014). In the field of simulation, a discrete-event simulation (DES) models the operation of a system as a discrete sequence of events in time. Each event occurs at a particular instant in time and marks a change of state in the system (Robinson, 2004). The position of discrete event simulation in the different systems is shown in Fig. 2. 
A discrete-event simulation model is defined by three attributes (Bossel, 1994):

1. Stochastic: at least some of the system state variables are random;

2. Dynamic: the evolution time of the system state variables is important;

3. Discrete-event: events that occur at discrete time instances only make significant changes in the system state variables.

By definition, the nature of discrete-event simulation is the way that one does not actually experience with or modify an actual system. Instead, one develops and then works with a discrete-event simulation model. This matter is also declared in this paper. Since the probability density, distribution of the wind speed is apparently a continuous one so a method is proposed to transform the probability density distribution of the wind speed to probability density distribution of turbine power. The transformation is done in a way that we consider the rotation of the wind turbines made by the wind that is blowing. It is known that the power of the wind directly affects the speed of turbines so by testing the speed of turbines due to winds with different powers we can estimate the probability distribution function of the wind turbine power.

\section{Simulation Design}

In this section, a method to reach the probability distribution function of the wind turbine power is presented and the factors that affect the simulation are reviewed. Finally, the simulation model is proposed in this section. Based on (Grogg, 2005) total energy that may come to an imaginary area A during the time $t$ is:

$$
E=\frac{1}{2} m v^{2}=\frac{1}{2}(A v t \rho) v^{2}=\frac{1}{2} A t \rho v^{3},
$$

where $\rho$ is the density of the air that is in kilograms per cubic meter; $\mathrm{v}$ is the wind speed based on meter per second; AVt is the volume of the air passing through area $\mathrm{A}$. In this formulation, $\mathrm{A}$ is considered

perpendicular to the direction of the wind. $\frac{1}{2} \rho v^{2}$ is the kinetic energy of the moving air per unit volume. Nevertheless, we know that power is energy per unit time so the wind power flowing into area A is:

$$
P=\frac{E}{t}=\frac{1}{2} A \rho v^{3}
$$

If $\mathrm{A}$ is equal to the rotor area of the wind turbine then the power that performs to the turbine is:

$$
P=\frac{1}{2} \pi r^{2} \rho v^{3}
$$

In this formulation, $r$ is the radius of the rotor based on the meter. When the wind blows into the turbine it affects the wind speed and this fraction cause lower efficiency in transforming the wind energy to the turbine. Albert Betz in 1919 proved that a turbine could take advantage of maximum 59 percent of the wind that blows on its way so coefficient $\alpha$ is added to the Eq. (16).

$$
P=\frac{1}{2} \alpha \pi r^{2} \rho v^{3}
$$

In Eq. (17), the unit of power is the watt. Fig. 3 demonstrates a typical wind turbine power output with wind speed. As it is shown in Figure 3, the output power is kept constant when wind speed is higher than the rated wind velocity, even though the wind turbine has the potential to produce more power. This matter happens because there is a risk of damage to the rotor. As a result, a braking system is employed to bring the rotor to a standstill. This limit is called the rated power output speed and is usually around 14 meters per second (Billinton \& Bai, 2004; Wang \& Nehrir, 2008). Moreover, it can be observed that after wind speed exceeds 25 meters per second the system is taken out of operation to protect its components. This limit is called cutout speed and is usually around 25 meters per second. 


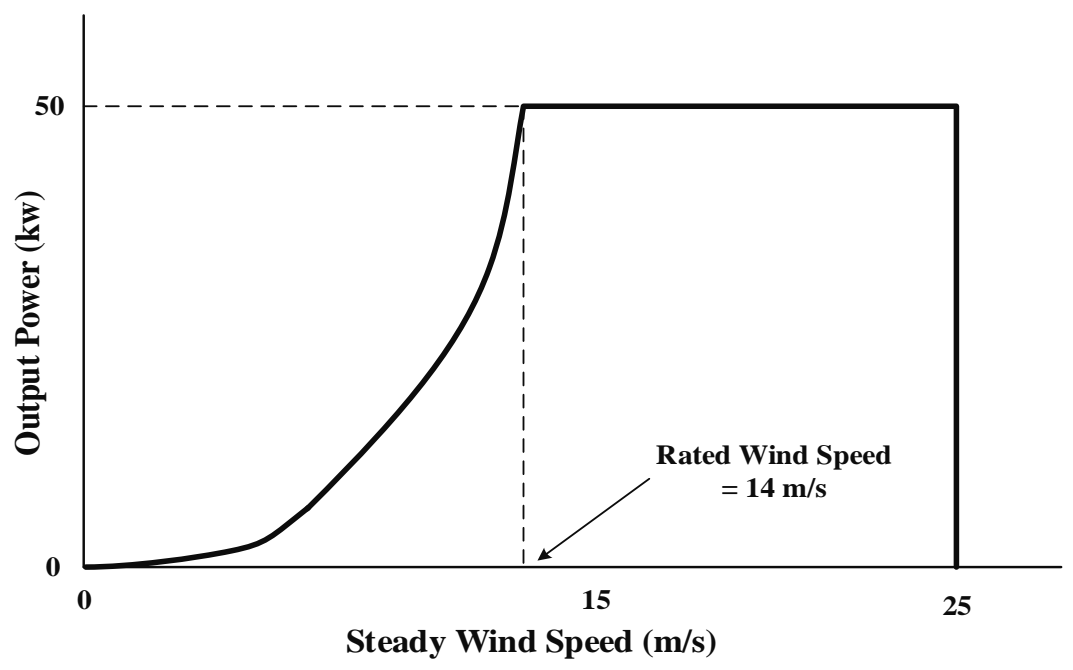

Fig. 3. Typical wind turbine power output with wind speed

However, it is a matter of common observation that the wind is not steady. Thus in order to calculate the power delivered by a wind turbine from its power curve, it is inevitable to recognize the probability density distribution of the wind speed. To estimate the frequency of wind speeds at a particular location, a probability distribution function often fits the observed data. However, different locations have different wind speed distributions but based on researches wind speed distributions of hourly/tenminute in many locations closely follows the Weibull model (Dorvlo, 2002; Seguro \& Lambert, 2000). Moreover a Rayleigh distribution can be used to simply estimate the probability distribution function of the wind speed that is equivalent to a Weibull distribution with $\mathrm{k}=2$ (Celik, 2004).

The probability distribution function of a Weibull random variable $\mathrm{x}$ is:

$$
f(x ; \lambda, k)= \begin{cases}\frac{k}{\lambda}\left(\frac{x}{\lambda}\right)^{k-1} e^{-\left(\frac{x}{\lambda}\right)^{k}} & \mathrm{x} \geq 0 \\ 0 & \mathrm{x}<0\end{cases}
$$

where $k>0$ is the shape parameter, $\lambda>0$ is the scale parameter of the scale parameter of the distribution. The mean and variance of Weibull distribution function can be expressed as:

$$
\begin{aligned}
& E(x)=\lambda \Gamma\left(1+\frac{1}{k}\right) \\
& \operatorname{Var}(x)=\lambda^{2}\left[\Gamma\left(1+\frac{2}{k}\right)-\left(\Gamma\left(1+\frac{1}{k}\right)\right)^{2}\right]
\end{aligned}
$$

In which $\Gamma\left(1+\frac{1}{k}\right)$ is the value of the Gamma function for $\left(1+\frac{1}{k}\right)$ that is:

$$
\Gamma(z)=\int_{0}^{\infty} t^{z-1} e^{-t} d t
$$

In addition, the cumulative distribution function is as below:

$$
F(x ; \lambda, k)= \begin{cases}1-e^{-\left(\frac{x}{\lambda}\right)^{k}} & x \geq 0 \\ 0 & x<0\end{cases}
$$


We already proved that the power output from a wind turbine is a function of the speed that a turbine can get (Eq. (17)). Clearly, based on Figure 3 the speed of a turbine varies with steady wind speed.

It is proved that if $x$ is a random variable on $\Omega$ set and $g$ is a function so that $g: \mathfrak{R} \rightarrow \mathfrak{R}$ then $Y=g(x)$ is also a random variable on $\Omega$ set. The cumulative distribution function of $\mathrm{Y}$ is:

$$
F_{y}(y)=P(g(x) \leq y)
$$

To calculate the probability density function of $y$ in case function $g$ is invertible (means that $g^{-1}$ exists), and also increasing, then equation (23) can be extended to:

$$
F_{y}(y)=P(g(x) \leq y)=P\left(x \leq g^{-1}(y)\right)=F_{x}\left(g^{-1}(y)\right)
$$

If we substitute $v$ in Eq. (17) with its probability function that is considered to be a Weibull probability function. Then, provided Eq. (17) being an invertible and non-decreasing function based on $v$, Eq. (24) can be used to calculate the probability function of turbine power. Since $P=\frac{1}{2} \alpha \pi r^{2} \rho v^{3}$ it can simply be transformed into:

$$
v=\left(\frac{P}{\frac{1}{2} \alpha \pi r^{2} \rho}\right)^{\frac{1}{3}}
$$

That is a unique function and clearly, when $p$ increases $v$ increases subsequently; thus, this is an increasing invertible function. Note that as already mentioned when $v$ exceeds the rated output wind, the system remains in a constant output and when it exceeds the cutout speed, the system stops operating. Then, to calculate the turbine power probability function $g^{-1}(y)$ is replaced by equation (24) and the cumulative distribution function $F$ would be a Weibull that is calculated in equation (22). Therefore, we have:

$$
F(x ; \lambda, k)=F_{x}\left(\frac{P}{\frac{1}{2} \alpha \pi r^{2} \rho}\right)^{\frac{1}{3}}=1-e^{-\left(\frac{\frac{1}{3} \frac{P}{\frac{1}{2} \alpha \pi r^{2} \rho}}{\lambda}\right)^{k}}
$$

This equation equals to:

$$
\left.P\left(x \leq\left(\frac{P}{\frac{1}{2} \alpha \pi r^{2} \rho}\right)^{\frac{1}{3}}\right)=\int_{0}^{\frac{P}{\frac{1}{2} \alpha \pi r^{2} \rho}}\right)^{\frac{1}{3}} \frac{k}{\lambda}\left(\frac{x}{\lambda}\right)^{k-1} e^{-\left(\frac{x}{\lambda}\right)^{k}} d x
$$

Calculating the integral in Eq. (27) results in Eq. (28) that is the turbine power cumulative distribution function.

$$
\left(\frac{P}{\frac{1}{2} \alpha \pi r^{2} \rho} \int_{0}^{\frac{1}{3}} \frac{k}{\lambda}\left(\frac{x}{\lambda}\right)^{k-1} e^{-\left(\frac{x}{\lambda}\right)^{k}} d x=-e^{-\left(\frac{x}{\lambda}\right)^{k}} \mid\left(\frac{P}{\frac{1}{2} \alpha \pi r^{2} \rho}\right)^{-\left(\frac{P}{\frac{1}{3} \alpha \pi r^{2} \rho}\right)^{\frac{1}{3}}}\right)^{k}=-e^{\left(\frac{1}{2}\right.}+1
$$

By differentiating the right side of Eq. (28) with respect to $p$, the probability density functions of turbine power can be calculated: 
$f_{P}(p)=\frac{d F_{p}(p)}{d p}=\frac{d}{d p}\left(-e^{\left.-\frac{P}{\frac{1}{2} \alpha \pi r^{2} \rho}\right)^{\frac{k}{3}}}+1\right)$
$=\frac{1}{\lambda^{k}} \frac{k}{3}\left(\frac{P}{\frac{1}{2} \alpha \pi r^{2} \rho}\right)^{\frac{k}{3}-1}\left(\frac{1}{\frac{1}{2} \alpha \pi r^{2} \rho}\right)^{\left.-\frac{P}{\lambda^{k}}\right)^{\frac{1}{2} \alpha \pi r^{2} \rho}}$

Thus, the probability density functions of turbine power would be:

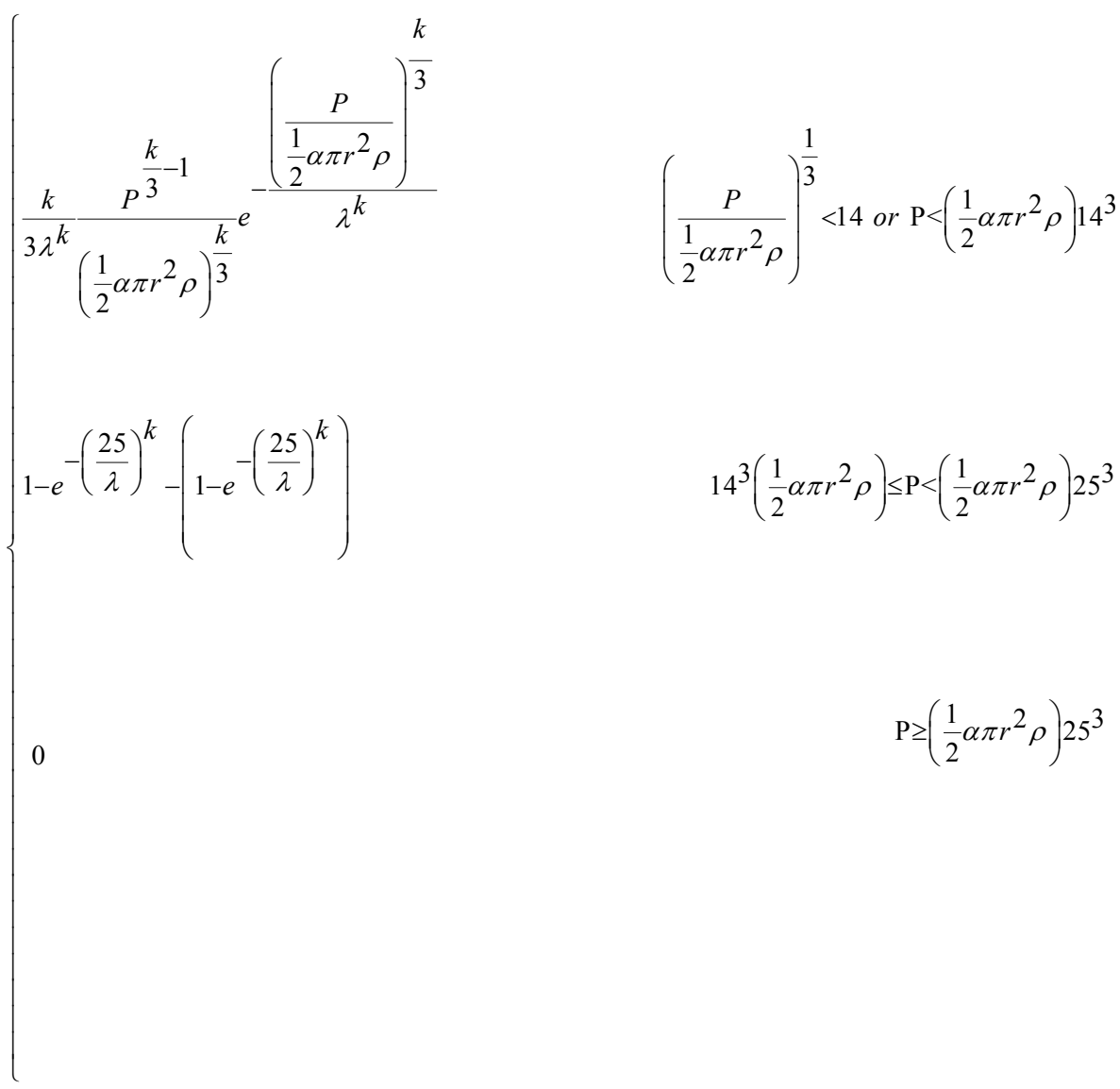

In the second row of Eq. (30) rated wind speed is considered so that when the wind speed is less than 14 meters per seconds, the probability density function of turbine power can be used, otherwise the probability of $(14<V<25)$ should be calculated. In this probability, the system works steadily and by increasing the wind speed the power does not increase. For $(25 \leq V)$ or $\left(\left(\frac{1}{2} \alpha \pi r^{2} \rho\right) 25^{3} \leq \mathrm{P}\right)$ system is taken out of operation in order to protect its components. 
After these calculations, this function can be used to generate random variables related to turbine power. In this function, the parameter that is changeable by the place of turbine is $\rho$ the density of the air. Note that $\alpha$ changes for different kind of turbines but the place of the turbine does not directly affect this parameter; therefore, we do not consider $\alpha$ as a variable of the simulation.

The mass per unit volume of atmospheric gases is called density of air. Air density and altitude have a reverse connection, so that decreasing the attitude causes increasing air density. It also changes with variation in temperature or humidity. According to International Standard Atmosphere (ISA), at sea level and at $15^{\circ} \mathrm{C}$ the air has a density of approximately $1.225 \mathrm{~kg} / \mathrm{m} 3(0.0023769 \mathrm{slugs} / \mathrm{ft} 3)$.

Since in this paper nominated locations to locate wind plants are in different geographic positions; thus, they differ in terms of attitude, mean temperature during the year and humidity factors. Therefore, these factors are considered in simulation model in addition to wind speed.

Based on Table 1 increasing the temperature decreases the quantity of $\rho$. Moreover, increasing altitude decreases density of air $(\rho)$.

\section{Table 1}

Density of air sensitivity against Temperature and Altitude

\begin{tabular}{lc|cc}
\hline Temperature $\mathrm{T}$ in ${ }^{\circ} \mathrm{C}$ & $\begin{array}{c}\text { Density of air } \rho \text { in } \\
\mathrm{kg} / \mathrm{m}^{\wedge} 3\end{array}$ & $\begin{array}{c}\text { Altitude } \\
(\mathrm{m})\end{array}$ & $\begin{array}{c}\text { Density of air } \rho \text { in } \\
\mathrm{kg} / \mathrm{m}^{\wedge} 3\end{array}$ \\
\hline 35 & 1.1455 & 0 & 1.177 \\
30 & 1.1644 & 100 & 1.164 \\
25 & 1.1839 & 250 & 1.143 \\
20 & 1.2041 & 500 & 1.110 \\
15 & 1.225 & 800 & 1.070 \\
10 & 1.2466 & 1100 & 1.032 \\
5 & 1.269 & 1400 & 0.995 \\
0 & 1.2922 & 1600 & 0.971 \\
-5 & 1.3163 & 1900 & 0.935 \\
-10 & 1.3413 & 2100 & 0.912 \\
-15 & 1.3673 & 2300 & 0.890 \\
-20 & 1.3943 & 2600 & 0.857 \\
-25 & 1.4224 & 3000 & 0.814 \\
\hline
\end{tabular}

All the items that results from the simulation phase are listed in Table 2.

Table 2

Items Considered in Simulation

\begin{tabular}{ll}
\hline Item No & Item Description \\
\hline 1 & Attitude of the scenario location \\
2 & Mean temperature of scenario location \\
3 & Mean humidity of scenario location \\
4 & System maintenance and Failure \\
5 & Demand fluctuation during 24 hours a day \\
6 & Power wasted \\
7 & Wind speed probability distribution characteristics \\
\hline
\end{tabular}

Items 1, 2 and 3 in Table 2, affect the parameter $\rho$ (density of the air) in the probability distribution function of produced power. The density of the air is determined Based on the formulation below (Davis, 1992; Mujumdar, 1996):

$$
\rho=\left(\frac{P}{R_{d} \times T}\right) \times\left(1-\frac{0.378 \times P_{v}}{P}\right)
$$


where:

$\rho=$ Density of the air $\left(\mathrm{kg} / \mathrm{m}^{3}\right)$

$P_{v}=$ Pressure of water vapor or partial pressure (Pascals)

$P=$ Total air pressure (Pascals)

$R_{v}=$ Gas constant for water vapor

$\mathrm{R}=$ Universal gas constant that is 8314.32

$M_{d}=$ Molecular weight of dry air that is $28.964(\mathrm{gm} / \mathrm{mol})$

$M_{v}=$ Molecular weight of water vapor that is $18.016(\mathrm{gm} / \mathrm{mol})$

$\mathrm{T}=$ Temperature, $\operatorname{deg} \mathrm{K}=\operatorname{deg} \mathrm{C}+273.15$

By replacing $P$ with formulation below, we reach a function for density of the air based on humidity, temperature, and attitude above sea level (Aras, Erdoğmuş, \& Koç, 2004):

$$
P=101325\left(1-2.25577 \times 10^{5} h\right)^{5.25588}
$$

where:

$\mathrm{P}=$ Air pressure (Pascals)

$\mathrm{h}=$ Attitude above sea level (m)

The final formulation that would be used to determine density of the air in the probability distribution function of turbine power is:

$$
\rho=\left(\frac{101325\left(1-2.25577 \times 10^{5} h\right)^{5.25588}}{R_{d} \times T}\right) \times\left(1-\frac{0.378 \times P_{v}}{P}\right)
$$

Item number 4 in Table 2 responds to the time that the system is unavailable and maintenance should be done on the turbines. By experience, the distribution of the turbine failure is considered to be exponential.

Item 5 considers demand fluctuations during a day. A day is divided into three intervals. First interval is from $8 \mathrm{AM}$ to $16 \mathrm{PM}$ that the demand and consumption of electricity is high due to industrial and office usage. Second interval is from 16 PM to 24 PM that has the highest demand among three parts because of the need for electricity in purpose of illumination. The last interval that has the lowest consumption rate is from $24 \mathrm{PM}$ to $8 \mathrm{AM}$.

Item 7 deals with the wind speed characteristics that are demonstrated in wind Weibull distribution function. Parameter $k$ is the shape parameter and $\lambda$ that is the scale parameter and in our problem is equal to 0 , but because this make the probability function infinite a very small number is determined for this parameter.

The output measures of the simulation phase that are the input for the DEA phase are listed in Table 3.

\section{Table 3}

The output measures of the simulation phase

\begin{tabular}{ll}
\hline Output Measures No & Output Measures \\
\hline 1 & Time out of Service \\
2 & $\begin{array}{l}\text { Amount of demands that are satisfied through other power resources rather than wind } \\
\text { plants }\end{array}$ \\
3 & $\begin{array}{l}\text { Amount of power that is wasted in wind plant due to lack of demand for it ( since } \\
\text { electricity can't be saved) }\end{array}$ \\
\hline 5 & Amount of demands that are satisfied the wind plants \\
\hline
\end{tabular}


It is assumed that at each nominated location, 25 wind plants are installed in a wind farm and they have $500 \mathrm{~kW}$ turbines.

In the simulation model, it is assumed that the power produced by wind can be stored for 10 minutes so if there is no demand for that power it will be wasted. Note that the usage of wind-generated electricity has priority toward other resources. The simulation phase has been carried out in AweSim simulation software for 100 repetitions in which each repetition was about simulating the model for 720 hours equal to one month. The simulation has been applied for every location candidate and the results are stored in Table 4.

\section{DEA Structure}

From the viewpoint that some indicators and measures to select the best location for the wind plant are deterministic; thus, the DEA phase should consider these measures as well as the measures that have resulted from the simulation phase.

Azadeh et al. (2011) in their study take account of location optimization of the wind plants by an integrated hierarchical data envelopment analysis. They introduced some indicators that were adapted from (Aras et al., 2004) work. These indicators are as follows:

- Population and human labor: Every industrial unit should have a low distance to the population who that industry is going to serve. Wind plant follows this matter too. Therefore, the closer the plant is to a mass population, the better. As a result, the nearest population to the scenario location is considered as an indicator.

- Distance of power distribution networks form the demand point: Proximity to the demand point has always been an important factor in location optimization problem. The transportation cost of materials for constructing the plant and the maintenance cost are directly related to the distance of power distribution networks form the demand point.

- Land cost: Apparently this indicator effectively influence the cost of constructing a wind plant.

- The intensity of natural disasters occurrence: Natural disasters such as earthquake, storm and fluid can harm the plant easily. Therefore, in selecting the optimum location to build a plant, this indicator should highly be regarded.

- Quantity of proper geological areas: A wind plant cannot be built in every ground. The ground slope, material and grade of soil and many more items affect building a plant on that ground.

Some of these indicators are used in this study as well.

\section{Computational Experiment}

In this section, we apply location optimization of wind plants in 24 nominal locations in Iran to examine the applicability of the model. The locations are the DMUs of the DEA problem. Table 4 presents the values of simulation phase parameters the for these locations. This information is gathered from http://www.weatherbase.com/ and http://www.suna.org.ir websites. Table 5 shows the results of the simulation phase for these locations. Results of simulation phase are consisted of time out of service (second per year) for each plant that is calculated based on the maintenance time of each plant; satisfied demand through wind plants $(\mathrm{GWh} /$ day) that is the average amount of demand directly satisfied by the plant; satisfied demand from other resources (GWh/day) that is the amount of demand satisfied through other power resources; wasted power (GWh/day) that since the electricity power can't be stored for a long time should be considered and average power generated ( $\mathrm{GWh} /$ day) that is the average amount of electricity power generated by the plant in a day.

Moreover, the values of indicators that were discussed in previous section are listed in Table 6 . The indicators are population and human labor; distance of power distribution networks form the demand point; land cost; the intensity of natural disasters occurrence; and quantity of proper geological areas. These data are adapted from (Azadeh et al., 2011). 
Table 4

Values of parameters of simulation phase

Location

Wind Speed Probability

Distribution

Attitude (m) Mean Temperature (C)

\begin{tabular}{llllll}
\hline Abadan & 10 & 25 & $43 \%$ & 5.57 & 1.16 \\
Ahvaz & 21 & 25 & $44 \%$ & 4.06 & 0.84 \\
Ardestan & 1206 & 11.5 & $47 \%$ & 4.87 & 0.94 \\
Bandar abbas & 10 & 27 & $67 \%$ & 4.74 & 1.01 \\
Birjand(khor) & 1490 & 18 & $34 \%$ & 4.01 & 1.09 \\
Boushehr & 18 & 25 & $64 \%$ & 4.80 & 1.03 \\
Hamedan & 1731 & 11 & $51 \%$ & 3.80 & 1.09 \\
Karaj & 1380 & 16 & $48 \%$ & 4.31 & 1.07 \\
Kerman & 1753 & 18 & $32 \%$ & 5.13 & 0.99 \\
Kermanshah & 1483 & 14 & $56 \%$ & 4.09 & 1.16 \\
Khoramabad & 1125 & 17 & $49 \%$ & 4.54 & 1.27 \\
Mahabad & 1320 & 12 & $57.5 \%$ & 2.57 & 1.25 \\
Manjil & 396 & 17 & $63 \%$ & 7.32 & 1.16 \\
Meimeh & 1956 & 11.5 & $47 \%$ & 4.20 & 0.93 \\
Neyshabor & 1350 & 14 & $46 \%$ & 4.45 & 1.15 \\
Oroumiye & 1363 & 12 & $23 \%$ & 3.22 & 0.89 \\
Sabzevar & 941 & 16 & $40 \%$ & 5.11 & 1.18 \\
Shahrekord & 2040 & 11 & $52 \%$ & 4.19 & 0.82 \\
Shiraz & 1490 & 18 & $40 \%$ & 4.12 & 0.97 \\
Tabriz & 1345 & 12 & $50 \%$ & 3.50 & 1.04 \\
Tehran & 1190 & 17 & $39 \%$ & 5.20 & 1.19 \\
Yazd & 1230 & 19 & $30 \%$ & 4.51 & \\
\hline Zabol & 470 & 22 & $32 \%$ & 5.74 & \\
Zahedan & 1344 & 20 & $22 \%$ & 5.40 & \\
\hline
\end{tabular}

Table 5

$\underline{\text { Results of simulation phase that are considered as input and output measures for DEA phase }}$

\begin{tabular}{|c|c|c|c|c|c|}
\hline \multirow[b]{2}{*}{ Location } & \multirow{2}{*}{\begin{tabular}{l}
\multicolumn{1}{c}{ Input } \\
Time out of \\
Service \\
(s per year)
\end{tabular}} & \multicolumn{4}{|c|}{ Output } \\
\hline & & $\begin{array}{l}\text { Satisfied Demand } \\
\text { Through Wind Plant } \\
\text { (GWh/day) }\end{array}$ & $\begin{array}{l}\text { Satisfied Demand } \\
\text { From Other } \\
\text { Resources } \\
\text { (GWh/day) }\end{array}$ & $\begin{array}{l}\text { Wasted } \\
\text { Power } \\
\text { (GWh/day) }\end{array}$ & $\begin{array}{l}\text { Average Power } \\
\text { Generated } \\
\text { (GWh/day) }\end{array}$ \\
\hline Abadan & $5.75 \mathrm{E}+05$ & 1.06 & 2.42 & 0.13 & 1.17 \\
\hline Ahvaz & $5.34 \mathrm{E}+05$ & 0.79 & 8.17 & 0.05 & 0.75 \\
\hline Ardestan & $4.81 \mathrm{E}+05$ & 0.96 & 1.18 & 0.12 & 0.84 \\
\hline Bandar abbas & $4.32 \mathrm{E}+05$ & 1.13 & 8.41 & 0.05 & 1.39 \\
\hline Birjand (khor) & $4.90 \mathrm{E}+05$ & 0.93 & 2.84 & 0.08 & 0.69 \\
\hline Boushehr & $4.29 E+05$ & 1.06 & 3.79 & 0.08 & 1.37 \\
\hline Hamedan & $6.12 \mathrm{E}+05$ & 0.80 & 7.32 & 0.06 & 1.21 \\
\hline Karaj & $7.80 \mathrm{E}+05$ & 0.94 & 16.56 & 0.02 & 0.93 \\
\hline Kerman & $4.82 \mathrm{E}+05$ & 1.11 & 7.46 & 0.08 & 1.13 \\
\hline Kermanshah & $5.80 \mathrm{E}+05$ & 0.84 & 8.49 & 0.07 & 1.19 \\
\hline Khoramabad & $7.35 \mathrm{E}+05$ & 0.96 & 5.10 & 0.08 & 1.68 \\
\hline Mahabad & $7.58 \mathrm{E}+05$ & 0.85 & 2.17 & 0.11 & 0.93 \\
\hline Manjil & $7.37 \mathrm{E}+05$ & 1.93 & 0.40 & 0.35 & 1.96 \\
\hline Meimeh & $7.19 \mathrm{E}+05$ & 1.16 & 1.78 & 0.15 & 0.83 \\
\hline Neyshabor & $6.39 \mathrm{E}+05$ & 1.12 & 2.98 & 0.07 & 1.27 \\
\hline Oroumiye & $6.30 \mathrm{E}+05$ & 0.92 & 6.87 & 0.12 & 1.11 \\
\hline Sabzevar & $5.02 \mathrm{E}+05$ & 1.04 & 3.14 & 0.18 & 1.48 \\
\hline Shahrekord & $5.45 \mathrm{E}+05$ & 0.77 & 1.98 & 0.06 & 0.60 \\
\hline Shiraz & $7.75 \mathrm{E}+05$ & 0.88 & 12.41 & 0.04 & 0.85 \\
\hline Tabriz & $6.05 \mathrm{E}+05$ & 0.97 & 15.87 & 0.04 & 0.93 \\
\hline Tehran & $5.86 \mathrm{E}+05$ & 1.19 & 65.98 & 0.00 & 1.78 \\
\hline Yazd & $4.28 \mathrm{E}+05$ & 1.15 & 5.47 & 0.08 & 1.03 \\
\hline Zabol & $6.88 \mathrm{E}+05$ & 1.41 & 1.59 & 0.21 & 1.39 \\
\hline Zahedan & $7.73 \mathrm{E}+05$ & 1.18 & 4.88 & 0.08 & 1.27 \\
\hline
\end{tabular}




\section{Table 6}

The values of indicators for nominated locations

\begin{tabular}{|c|c|c|c|c|}
\hline \multirow[b]{2}{*}{ Location } & \multicolumn{3}{|c|}{ Output } & \multirow{2}{*}{$\begin{array}{c}\text { Input } \\
\text { Intensity of natural } \\
\text { disasters } \\
\text { occurrence }\end{array}$} \\
\hline & $\begin{array}{l}\text { Quantity of proper } \\
\text { Geological areas }\end{array}$ & $\begin{array}{l}\text { Quantity of proper } \\
\text { Topographical areas }\end{array}$ & $\begin{array}{l}\text { Population and } \\
\text { human labor }\end{array}$ & \\
\hline Abadan & $36,490.3$ & 691.1 & 41,215 & 19.4 \\
\hline Ahvaz & $36,490.3$ & 691.1 & 160,996 & 19.4 \\
\hline Ardestan & $80,296.3$ & $10,484.1$ & 29,030 & 7.3 \\
\hline Bandar abbas & $55,862.6$ & 2854 & 54,716 & 14.9 \\
\hline Birjand(khor) & $226,316.2$ & 80,892 & 25,522 & 20.4 \\
\hline Boushehr & $15,747.9$ & 891.2 & 28,728 & 8.7 \\
\hline Hamedan & $14,928.7$ & 274.5 & 80,256 & 3 \\
\hline Karaj & $27,784.6$ & 2898.4 & 188,194 & 5.6 \\
\hline Kerman & $153,426.3$ & 3154.4 & 76,998 & 12.9 \\
\hline Kermanshah & $16,738.3$ & 1745.7 & 138,597 & 4.2 \\
\hline Khoramabad & 17,827 & 1378.9 & 54,563 & 5.1 \\
\hline Mahabad & $24,081.1$ & 1755.2 & 50,000 & 8.9 \\
\hline Manjil & $10,655.8$ & 280.3 & 25,263 & 7.7 \\
\hline Meimeh & $80,296.3$ & $10,484.1$ & 55,956 & 8.3 \\
\hline Neyshabor & $226,316.2$ & 80,892 & 41,195 & 20.4 \\
\hline Oroumiye & $24,081.1$ & 1755.2 & 87,040 & 12 \\
\hline Sabzevar & $226,316.2$ & 80,892 & 34,148 & 18 \\
\hline Shahrekord & 11,281 & 6.5 & 20,095 & 3.7 \\
\hline Shiraz & $83,693.9$ & 5725.9 & 210,605 & 24.3 \\
\hline Tabriz & 31,271 & 1797.3 & 238,209 & 7.8 \\
\hline Tehran & $27,784.6$ & 2898.4 & $1,351,769$ & 5.6 \\
\hline Yazd & $56,358.9$ & $11,761.9$ & 65,355 & 3.6 \\
\hline Zabol & $154,642.3$ & $10,857.5$ & 20,177 & 7.6 \\
\hline Zahedan & $154,642.3$ & $10,857.5$ & 83,904 & 7.6 \\
\hline
\end{tabular}

Efficiency scores and ranking the nominated locations is presented in Table 7.

Table 7

Efficiency scores and ranking the nominated locations

\begin{tabular}{lccc}
\hline Location & Technical Efficiency & Full Efficiency & Rank \\
\hline Abadan & 0.654 & 0.840 & 10 \\
Ahvaz & 0.582 & 0.698 & 14 \\
Ardestan & 0.470 & 0.647 & 9 \\
Bandar abbas & 0.633 & 0.854 & 7 \\
Birjand(khor) & 0.714 & 0.979 & 11 \\
Boushehr & 0.518 & 0.823 & 18 \\
Hamedan & 0.669 & 0.564 & 4 \\
Karaj & 0.410 & 0.618 & 23 \\
Kerman & 0.784 & 1.016 & 24 \\
Kermanshah & 0.349 & 0.563 & 15 \\
Khoramabad & 0.296 & 0.549 & 1 \\
Mahabad & 0.434 & 0.675 & 8 \\
Manjil & 1 & 1.32 & 3 \\
Meimeh & 0.614 & 0.950 & 13 \\
Neyshabor & 1 & 1.021 & 12 \\
Oroumiye & 0.486 & 0.769 & 20 \\
Sabzevar & 0.532 & 0.782 & 17 \\
Shahrekord & 0.364 & 0.601 & 21 \\
Shiraz & 0.478 & 0.647 & 19 \\
Tabriz & 0.398 & 0.592 & 6 \\
Tehran & 0.417 & 0.612 & 2 \\
Yazd & 0.764 & 0.987 & 5 \\
\hline Zabol & 1 & 1.110 & 1 \\
Zahedan & 0.851 & 12 & \\
\hline
\end{tabular}


Based on Table 7, best location or city for placing a wind plant is Manjil, after that Zabol has the best rank and Neyshabour, Kerman and Zahedan come next. Previous studies in Iran reveal that Manjil, Sabzevar and Zabol have the best potential to place a wind plant. Moreover the study by Azadeh et al. (2011) reports Manjil, Birjand, Zabol and Sabzevar as the best candidates. These results demonstrate that the results of this study are similar to other studies.

\section{Conclusion}

In this study, a model was proposed to find the optimum location for building a wind plant. The electric power generated by the wind plants is highly affected by the wind speed; therefore, a simulation approach has been proposed in the first phase of the model to handle the uncertainty of the wind speed. Moreover, a probability density function has been calculated for the output power of wind plant respect to the wind speed. In addition, for density of the air $(\rho)$ that is a critical parameter in the before mentioned probability function, a formulation has been presented. This formulation calculates the $\rho$ based on attitude, temperature and humidity. The density of the air directly affects the power generated by the turbines. In the second phase of the model, DEA deals with the selection and ranking the nominated locations. In this phase, input data of the DEA are two folded: some are derived from the simulation phase and some enter directly to the DEA. The indicators that were derived from the simulation phase were time out of service; the amount of demand that is satisfied through other power resources rather than wind plants; the amount of power that is wasted in wind plant due to lack of demand for it (since it is inefficient to save electricity for a long time); the amount of demand that is satisfied by the wind plants and the average power received from wind speed. The indicators that enter directly to DEA phase are quantity of proper geological areas; quantity of proper topographical areas; population and human labor; the intensity of natural disasters occurrence.

For future research, one can consider the simulation model with different turbine models. Moreover, a hierarchy model could be proposed to handle the connections between indicators. The fluctuations of the weather also can be a good area to work on in the simulation model. Using Fuzzy Data Envelopment Analysis (FDEA) for ranking the locations in a fuzzy environment can also be considered for future development of this paper.

\section{Acknowledgements}

The authors are greatly thankful to Dr. Emad Jazayeri for his valuable suggestions and comments on this paper.

\section{References}

Abdollahi, M., Arvan, M., Omidvar, A., \& Ameri, F. (2014). A simulation optimization approach to apply value at risk analysis on the inventory routing problem with backlogged demand. International Journal of Industrial Engineering Computations, 5, 603-620.

Abdollahi, M., Arvan, M., \& Razmi, J. (2014). An integrated approach for Supplier Portfolio Selection: Lean or Agile? Expert Systems with Applications, 42(1), 679-690

Al-Eraqi, A. S., Barros, C. P., Mustaffa, A., \& Khader, A. T. (2007). Evaluating the Location Efficiency of Arabian and African Seaports Using Data Envelopment Analysis (DEA).

Andersen, P., \& Petersen, N. C. (1993). A procedure for ranking efficient units in data envelopment analysis. Management science, 39(10), 1261-1264.

Andor, M., \& Hesse, F. (2011). A Monte Carlo Simulation comparing DEA, SFA and two simple approaches to combine efficiency estimates: CAWM discussion paper/Centrum für Angewandte Wirtschaftsforschung Münster.

Aras, H., Erdoğmuş, Ş., \& Koç, E. (2004). Multi-criteria selection for a wind observation station location using analytic hierarchy process. Renewable Energy, 29(8), 1383-1392.

Arvan, M., Tavakkoli-Moghaddam, R., \& Abdollahi, M. (2014). Designing a bi-objective and multi-product supply chain network for the supply of blood. Uncertain Supply Chain Management, 3(1), 57-68. 
Aytun Ozturk, U., \& Norman, B. A. (2004). Heuristic methods for wind energy conversion system positioning. Electric Power Systems Research, 70(3), 179-185.

Azadeh, A., Ghaderi, S., \& Maghsoudi, A. (2008). Location optimization of solar plants by an integrated hierarchical DEA PCA approach. Energy Policy, 36(10), 3993-4004.

Azadeh, A., Ghaderi, S., \& Nasrollahi, M. (2011). Location optimization of wind plants in Iran by an integrated hierarchical Data Envelopment Analysis. Renewable Energy, 36(5), 1621-1631.

Bhatnagar, R., \& Sohal, A. S. (2005). Supply chain competitiveness: measuring the impact of location factors, uncertainty and manufacturing practices. Technovation, 25(5), 443-456.

Billinton, R., \& Bai, G. (2004). Generating capacity adequacy associated with wind energy. Energy Conversion, IEEE Transactions on, 19(3), 641-646.

Bossel, H. (1994). Modeling and simulation: AK Peters Wellesley, MA.

Bowling, I. M., Ponce-Ortega, J. M. a., \& El-Halwagi, M. M. (2011). Facility location and supply chain optimization for a biorefinery. Industrial \& Engineering Chemistry Research, 50(10), 6276-6286.

Celik, A. N. (2004). A statistical analysis of wind power density based on the Weibull and Rayleigh models at the southern region of Turkey. Renewable Energy, 29(4), 593-604.

Charnes, A. (1994). Data envelopment analysis: theory, methodology, and application: Kluwer Academic Pub.

Charnes, A., Cooper, W. W., \& Rhodes, E. (1978). Measuring the efficiency of decision making units. European Journal of Operational Research, 2(6), 429-444.

Chatterjee, N., \& Bose, G. (2013). A COPRAS-F base multi-criteria group decision making approach for site selection of wind farm. Decision Science Letters, 2(1), 1-10.

Cooper, W. W. (2011). Handbook on data envelopment analysis: Springer Science+ Business Media.

Cooper, W. W., Seiford, L. M., \& Zhu, J. (2011). Data envelopment analysis: History, models, and interpretations: Springer.

Davis, R. S. (1992). Equation for the determination of the density of moist air (1981/91). Metrologia, 29(1), 6770.

Dorvlo, A. S. (2002). Estimating wind speed distribution. Energy Conversion and Management, 43(17), 23112318.

Farrell, M. J. (1957). The measurement of productive efficiency. Journal of the Royal Statistical Society. Series A (General), 120(3), 253-290.

Ganley, J. A., \& Cubbin, J. S. (1992). Public sector efficiency measurement: Applications of data envelopment analysis: Elsevier Science Inc.

Gendron, B., Khuong, P.-V., \& Semet, F. (2013). A Lagrangian-Based Branch-and-Bound Algorithm for the Two-Level Uncapacitated Facility Location Problem with Single-Assignment Constraints: Technical Report 2013-21, CIRRELT.

Gollowitzer, S., \& Ljubić, I. (2011). MIP models for connected facility location: A theoretical and computational study. Computers \& Operations Research, 38(2), 435-449.

Grogg, K. (2005). Harvesting the Wind: The Physics of Wind Turbines.

Guo, P. (2009). Fuzzy data envelopment analysis and its application to location problems. Information Sciences, 179(6), 820-829.

Klimberg, R. K., \& Ratick, S. J. (2008). Modeling data envelopment analysis (DEA) efficient location/allocation decisions. Computers \& Operations Research, 35(2), 457-474.

Marín, A. (2011). The discrete facility location problem with balanced allocation of customers. European Journal of Operational Research, 210(1), 27-38.

McMullen, P. R., \& Frazier, G. V. (1999). Using simulation and data envelopment analysis to compare assembly line balancing solutions. Journal of Productivity Analysis, 11(2), 149-168.

Mitropoulos, P., Mitropoulos, I., \& Giannikos, I. (2012). Combining DEA with location analysis for the effective consolidation of services in the health sector. Computers \& Operations Research, 40(9), 2241-2250.

Mujumdar, A. (1996). Techniques and Topics in Flow Measurement. Drying Technology, 14(7-8), 1909-1910.

Rentizelas, A., Tatsiopoulos, I., \& Tolis, A. (2009). An optimization model for multi-biomass tri-generation energy supply. Biomass and bioenergy, 33(2), 223-233.

Robinson, S. (2004). Simulation: the practice of model development and use: Wiley.

Seguro, J., \& Lambert, T. (2000). Modern estimation of the parameters of the Weibull wind speed distribution for wind energy analysis. Journal of Wind Engineering and Industrial Aerodynamics, 85(1), 75-84.

Talluri, S. (2000). Data envelopment analysis: models and extensions. Decision Line, 31(3), 8-11.

Wang, C., \& Nehrir, M. H. (2008). Power management of a stand-alone wind/photovoltaic/fuel cell energy system. Energy Conversion, IEEE Transactions on, 23(3), 957-967. 